\title{
Media Pembelajaran Interaktif Jarak Jauh Untuk Laboratorium Video Broadcasting Berbasis Virtual Reality Kolaboratif
}

\author{
Moh. Zikky ${ }^{*}$, Dwi Susanto ${ }^{2}$, Irfan Ramadhi ${ }^{3}$ \\ ${ }^{1,2,3}$ Departemen Teknologi Multimedia Kreatif, Politeknik Elektronika Negeri Surabaya, \\ Surabaya, Indonesia \\ *Email: zikky@pens.ac.id
}

\begin{abstract}
The current covid-19 pandemic demands us that distance learning must be operated and defined as well as possible for a while. No choice to attend the real classroom. A quite complicated problem is how to present practicum learning and laboratory work (especially for vocational education) in online media?. So, this application here to answer by presenting an interactive virtual laboratory which can be implemented with collaborative practitioners remotely. With Virtual Reality (VR) technology which is synchronized on the internet, the interaction between the supervisor and the practitioners (students who are practicing) are presented with avatar characters who are gathered in a virtual world. Beside they able to communicate with each other using voice, their avatars will also be presented in the virtual room of broadcasting laboratory as a team that capable to do practical work together. Furthermore, their avatars can shake hands, communicate with gestures, and all things look likes happens in the real- broadcasting laboratory. The broadcasting laboratory practicum activities here include virtual cameramen, video switching controllers, and manager or producer who organize these video-broadcasting activities, all of those activities will be presented with collaborative-remote virtual activities. By using the VR plugin on Steam, several multiplayer library packages on the Unity game engine, as well as character creation built with good inversekinematics rigging. Each player / user 3D Avatar character can be presented realistically and naturally.
\end{abstract}

Keywords: virtual broadcasting laboratory, distance learning, virtual reality, online practicum.

\begin{abstract}
Abstrak
Masa pandemi covid 19 saat ini menuntut kita agar pembelajaran jarak jauh bisa dilakukuan dengan interaktif dan sebaik mungkin. Permasalahan yang cukup rumit adalah bagaimana menghadirkan pembelajaran praktikum dan kerja-kerja laboratorium (terutama untuk pendidikan vokasi) dalam media daring. Maka perangkat ini hadir untuk menjawabnya dengan menghadirkan laboratorium virtual interaktif yang bisa dilakukan dengan kolaborasi praktikan dalam jarak jauh. Dengan teknologi Virtual Reality (VR) yang disinkronisasi dalam jaringan internet, interaksi antara pembimbing dengan para praktikan (para siswa/mahasiswa yang sedang melakukan praktek) disini dihadirkan dalam bentuk karakter avatar yang sedang berkumpul dalam dunia virtual. Masing-masing mereka selain dapat saling berkomunikasi menggunakan suara, avatar mereka juga akan dihadirkan dalam ruang lab broadcasting virtual sebagai satu tim yang mampu melakukan kerja praktek secara bersama. Bahkan avatar mereka bisa saling bersalaman, berkomunikasi dengan gerak gestur, dan segala hal seperti layaknya kejadian yang terjadi di laboratorium broadcasting dalam dunia nyata. Kegiatan praktikum laboratorium broadcasting disini meliputi pengarah kamera virtual, pengatur switching video, dan menejer atau produser yang mengatur jalannya kegiatan broadcasting tersebut, yang semuanya akan dihadirkan dalam bentuk aktivitas virtual secara kolaboratif-jarak jauh. Dengan menggunakan plugin VR pada Steam, beberapa paket library multiplayer pada game engine Unity, serta pembuatan karakter yang dibangun dengan penulangan (rigging) kinematika terbalik yang baik. Karakter 3D Avatar masing-masing pemain/pengguna mampu dihadirkan dengan realistis dan lebih natural.
\end{abstract}

Kata kunci : laboratorium broadcasting virtual, pembelajaran jarak jauh, virtual reality, praktikum daring. 


\section{Pendahuluan}

\subsection{Latar Belakang}

Kemunculan pandemi covid 19 diawal tahun 2020 telah menuntut kita berfikir keras bagaimana seluruh pembelajaran yang selama ini dilakukan dengan cara berkumpul dan bertatap muka di kelas atau laboratorium harus diganti ke dalam bentuk daring. Beruntungnya, hari ini manusia hidup pada jaman internet dan perangkat telekomunikasi moderen, sehingga kegiatan berkumpul dan komunikasi masih bisa dijalankan meskipun hanya bisa dilakuakn dalam dunia maya. Kondisi ini akhirnya juga merevolusi dan memaksa semua orang untuk berfikir bagaimana proses pembelajaran dapat tetap tersampaikan dengan baik di berbagai sekolah dan perguruan tinggi, baik dari segi medianya ataupun metode interaksinya. Elearning, webinar, dan pembelajaran jarak jauh lainnya merupakan salah satu revolusi yang mau tidak mau harus digunakan saat ini agar Pendidikan terus dapat berlangsung.

Dalam metode kuliah teori pendagogik, media ceramah dengan video interaktif atau webinar untuk Pendidikan Jarak Jauh (PJJ) masih relatif efektif, namun metode ceramah akan menjadi kurang efektif pada pelajaran yang butuh alat peraga atau laboratorium khusus. Hal ini terjadi karena perlakuan praktikum tidak bisa disamakan dengan pelajaran teori yang sebagian besar disampaikan dengan metode ceramah, kedekatan jarak bimbingan dosen kepada mahasiswa atau guru dan siswa pada proses praktikum sangat besar peran dan pengaruhnya. Sehingga media komputer dan internet yang dijadikan media utama dalam proses pembelajaran jarak jauh haruslah diupgrade perannya menjadi media yang bisa menyajikan lingkungan yang lebih dekat dan imersif antara murid dan guru (mahasiswa dan dosen) tersebut.

Salah satu alternatif pembelajaran jarak jauh praktikum saat ini yang sangat imersif dan efektif untuk mensimulasikan perangkat laboratorium bisa disimulasikan menggunakan media Virtual Reality (VR). Ada banyak perangkat laboratorium yang memungkinkan untuk dikonversi menjadi simulasi perangkat virtual, seperti praktikum bedah pasien, perakitan $\mathrm{PCB}$, praktikum reaksi kimia, membangun server untuk jaringan internet, dan lain sebagainya, sesuai dengan fungsi laboratorium tersebut. Perangkat yang cukup mempuni untuk membangun $V R$ praktikum virtual ini bisa dengan HTC Vive atau Oculus Touch. Kontroler HTC Vive atau Oculus mampu meniru gerakan tangan beserta posisinya, tombol-tombol pada perangkat tersebut juga mampu berperan sebagai interaksi pada tangan, seperti menirukan gerakan jari jemari, menggenggam, menunjuk, dan lain sebagainya

Dalam riset ini, laboratorium virtual dikembangkan untuk mensimulasikan aktivitas praktikum pada lab video broadcasting yang ada di kampus PENS. Laborarium virtual ini dibangun dengan konsep multiplayer kolaboratif, karena dalam proses shooting video, ada banyak kru yang terlibat. Sehingga meski dilakukan dengan konsep PJJ, masingmasing kru (praktikan) diharapkan dapat saling berkomunikasi satu-sama lain dalam lingkungan lab virtual tersebut meski posisi sebenarnya mereka berada di tempat yang saling berjauhan satu sama lain.

\subsection{Diskusi}

Ada beberapa riset termutakhir yang memanfaatkan teknologi Virtual Reality (VR) sebagai perangkat pembelajaran, khususnya dalam pembelajaran praktikum. Hal ini memang awalnya kebanyakan ditujukan bukan karena kondisi pandemi, melainkan untuk meminimalisasi resiko dan menjadikan praktikum dengan VR lebih ekonomis, karena perangkat praktikum yang dibuat dalam bentuk 3D sedemikian rupa ini bisa diduplikasi sebanyak mungkin sesuai kebutuhan institusi pendidikan yang bersangkutan.

Salah satu perusahaan yang memproduksi berbagai perangkat pembelajaran laboratorium dengan VR adalah 
Labster [1]. Labster membuat berbagai simulasi laboratorium berbasis realitas maya yang hampir bisa dikatakan sama persis dengan laboratorium nyatanya. Labster bahkan berkolaborasi dengan berbagai universitas terkemuka di dunia untuk membuat perangkat tersebut. Gambar 1.1 merupakan salah satu simulasi VR pada praktikum keselamatan kerja.

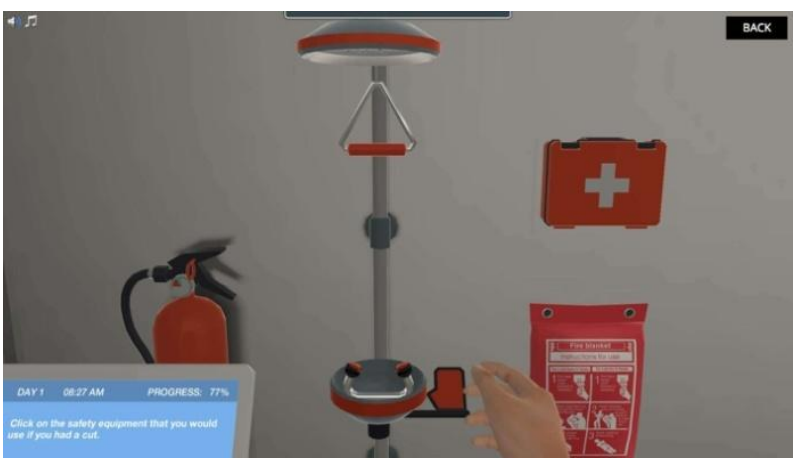

Gambar 1.1 Simulasi laboratorium praktikum keselamatan kerja berbasis VR yang dibuat Labster [1]

Dalam pengembangan lainnya, Sritrusta Sukaridhoto, dkk [2] mengembangkan laboratorium kimia virtual yang juga berbasis VR. Virtual Reality (VR) dibangun dengan menggunakan dua perangkat utama, yaitu Oculus Rift sebagai headset VR yang mampu menditeksi orientasi gerakan kepala dan Leap Motion sebagai sensor deteksi gerakan tangan user (pengguna)-nya.

Dalam pengembangnnya, meja kerja laboratorium dibangun dengan sebaik mungkin, efek reaksi kimia dibuat dengan partikel efek 3D yang mendekati keadaan aslinya, disana juga diberikan buku petunjuk praktikum yang diletakkan di depan user interface agar mudah dibaca oleh pengguna saat melakukan praktikum. Gambar 1.2. merupakan hasil pengembangan lab. Kimia virtual berbasis VR.

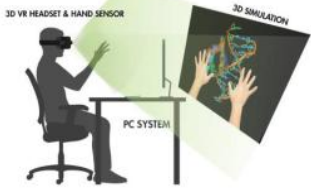

(a)

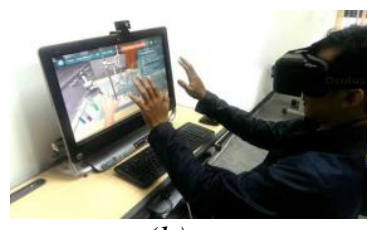

(b)

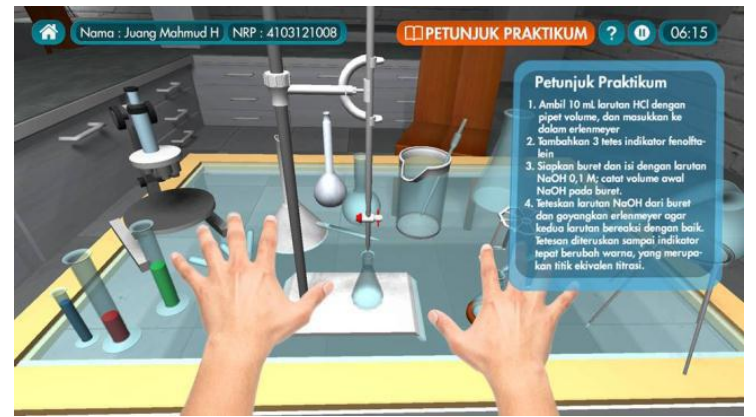

(c)

Gambar 1.2. Laboratorium kimia berbasis Virtual Reality: (a) Desain sistem, (b) Simulasi pengguna, (3) User Interface Sistem [2]

Kemudian dalam penelitian yang dilakukan sebelumnya, penulis juga telah mengembangkan sebuah media pembelajaran jarak jauh dengan materi sistem tata surya, dimana pengguna bisa menggunakan perangkat Leap Motion untuk melakukan interaksi tangan sederhana, contohnya seperti menunjuk planet dan melambaikan tangan [3] sebagaimana terlihat pada Gambar 1.3. Simulator tersebut juga sudah bisa melakukan interaksi berupa input suara yang bisa didengarkan oleh pengguna lain. Pada penelitian tersebut, tata surya sudah bisa terlihat dengan jelas dan dapat digunakan dengan baik dalam memberikan materi pembelajaran tata surya pada setiap planet yang ada.

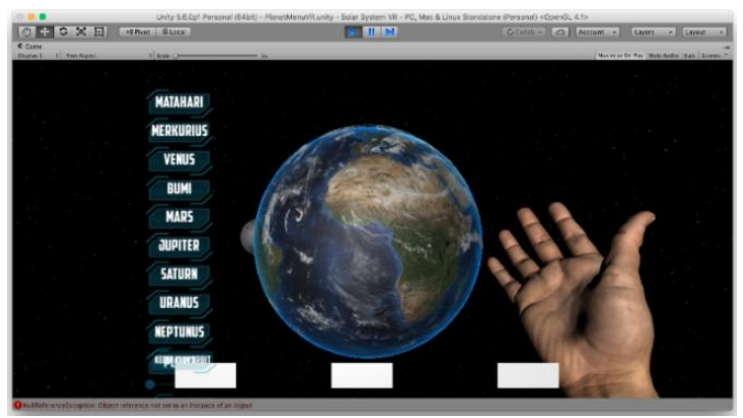

Gambar 1.3. Tampilan dari media pembelajaran jarak jauh sistem tata surya [3].

Sedangkan dalam Praktikum broadcasting umumnya dilakukan minimal oleh satu kameramen dan satu pengatur switch, atau akan lebih baik lagi misalkan ada beberapa kameramen yang standby, satu operator switcher yang bertugas memilih sorotan kamera yang pas secara realtime, dan produser 
yang bertanggung jawab penuh dalam mengarahkan proses broadcasting tersebut.

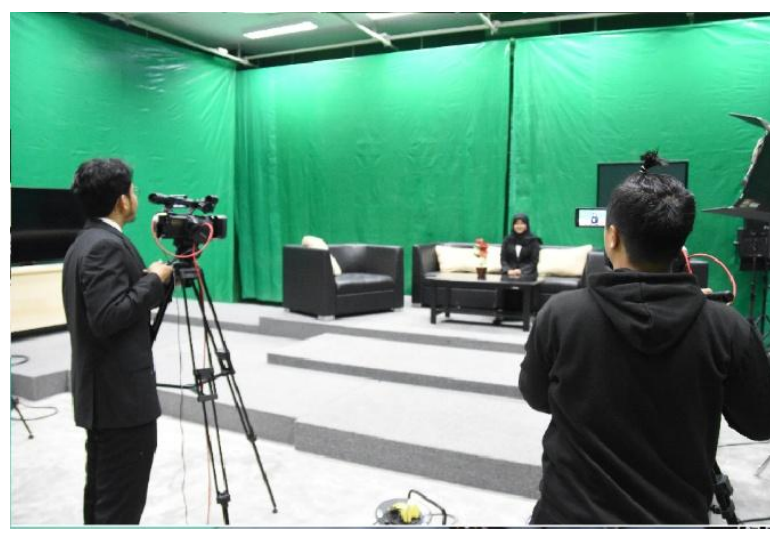

Gambar 1.4. Contoh pengambilan kamera dan operator switcher dalam lab broadcasting.

Beberapa perangkat yang harus tersedia saat melakukan praktikum pada video broadcasting yang dipraktekkan secara kolaboratif harus terdiri dari perangkat berikut ini:

\section{a) Switcher Televisi FOR-A Ginga VPS- $7000 U$}

Dalam pembuatan media praktikum ini, akan diujikan sesuai peralatan yang dipakai di laboratorium broadcasting PENS, yaitu FORA Ginga VPS-700OU [4]. Penampakan perangkat tersebut sebagaimana digambarkan pada 1.5.

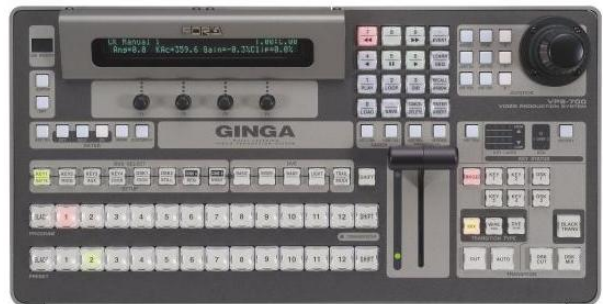

Gambar 1.5 Switcher Televisi dengan merk GINGA tipe FOR-A Ginga VPS-700OU [4]

Bagian-bagian pada perangkat FOR-A Ginga VPS-700OU ini jika dikelompokkan pada fungsinya, maka secara garis besar fungsi dari fitur perangkat tersebut sebagaimana Gambar 1.6.

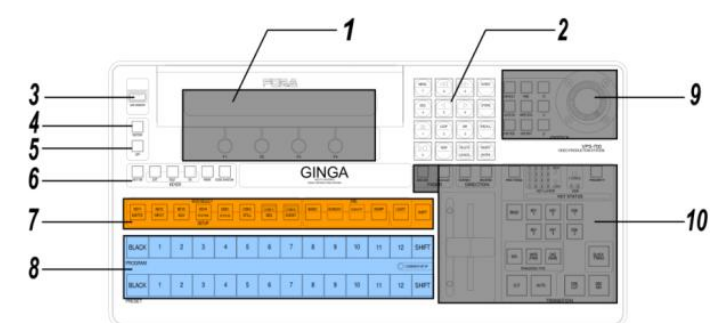

Gambar 1.6. Skema fungsi-fungsi yang ada pada Switcher VPS-700OU

Pada Gambar 1.6 terlihat fungsi tombol FOR-A Ginga VPS-700OU secara keseluruhan, namun akan diambil fungsi sederhana yang bisa mencakup latihan broadcasting skala kecil dan prototype inilah yang akan diadaptasi ke dalam media laboratorium virtual, antara lain:

1) Bagian nomer 1, yaitu Menu Display, berfungsi untuk memperlihatkan mode apa yang sedang berjalan pada Switcher tersebut. Misalkan mode switcher berada dalam mode siaga untuk berganti ke kamera 3 dengan transisi $C u t$, atau lainnya.

2) Bagian nomer 8, tombol-tombol tersebut berfungsi untuk mengatur kamera mana yang digunakan untuk output Preview dan Program.

3) Bagian nomor 10, tombol-tombol yang berfungsi untuk memberikan transisi ketika berpindah kamera, seperti penggunaan efek fede-in/fade-out efek umum yang digunakan agar transisi ketika berpindah kamera tidak kaku.

\section{b) Kamera Broadcasting}

Untuk kamera broadcasting yang akan dihubungkan ke switcher VPS-700OU tentu tidak harus spesifik fiturnya, karena dalam lab virtual ini cukup bisa menampilkan ruang yang disorot oleh kamera tersebut. Bentuk dari asset 3D kamera nanti akan dibuat seperti standarisasi kamera broadcasting studio seperti Sony HDC-2000 yang nampak pada Gambar 1.7. 


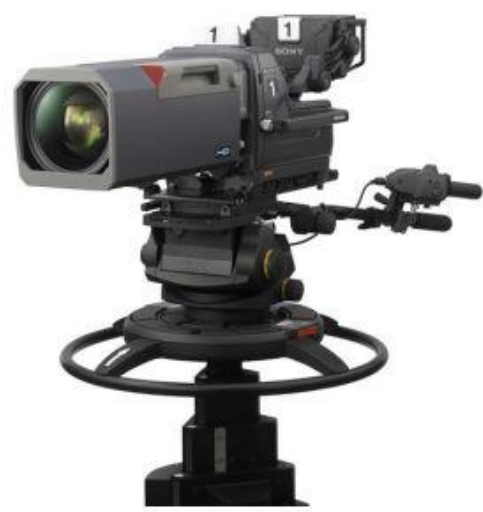

Gambar 1.7. Kamera pada Lab Broadcasting dengan tipe Sony HDC-2000 [5]

\section{Metoda Penelitian}

\subsection{Perancangan Sistem}

Perancangan sistem yang dibangun pada riset ini secara garis besar digambarkan pada skema Gambar 2.1.

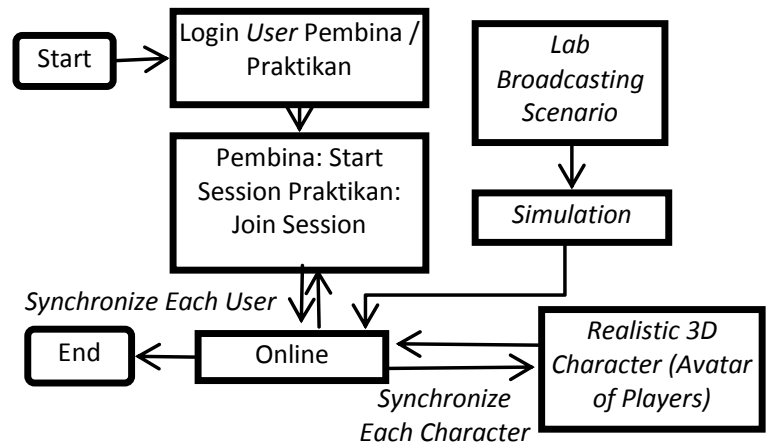

Gambar 2.1 Diagram Desain Media Pembelajaran

Untuk proses pengembangan simulasi yang digambarkan pada Gambar 2.1, perangkat utama yang digunakan dalam simulator VR ini adalah HTC Vive atau Oculus Rift. Perangkat tersebut digunakan sebagai controller sekaligus tampilan untuk melakukan interaksi didalam laboratorium broadcasting. Kacamata teropong sekaligus kontroler VR tersebut dihubungkan ke PC desktop yang memiliki koneksi internet agar interaksi media ini dapat dilakukan dengan pembelajaran jarak jauh. Gambar 2.2 merupakan tampilan perangkat VR yang digunakan.

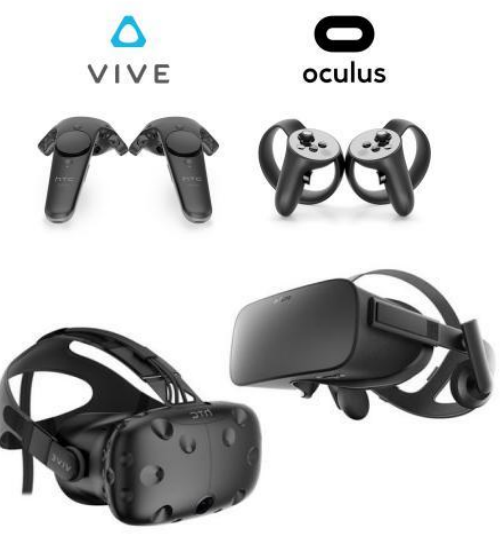

Gambar 2.2. Perangkat Virtual Reality

Selanjutnya, setiap pengguna akan login kedalam simulasi media pembelajaran, lalu memasukkan data pribadi berupa nama dan status (guru / siswa). Setiap pengguna akan diarahkan ke pembuatan avatar tepat setelah login. Jika login sebagai guru / admin, maka pengguna akan diarahkan ke pembuatan ruang sesi pembelajaran, lalu menunggu siswa / client untuk bergabung ke sesi yang telah dibuat. Guru tersebut bukan menunggu di suatu lobi tersendiri, namun menunggu langsung didalam laboratorium broadcasting di dunia maya dan bisa berinteraksi dengan obyek sekitar. Jika login sebagai siswa, maka pengguna akan diarahkan ke pemilihan sesi pembelajaran yang tersedia. Setelah memilih, siswa akan bergabung ke sesi tersebut bersama dengan pengguna lain dan pengguna yang bertindak sebagai guru atau admin. Disini simulator akan diarahkan ke bagian ruang kegiatan yang bisa dilakukan didalam laboratorium broadcasting, mulai dari praktikum yang paling mendasar sampai yang agak rumit. Seperti praktikum pengaturan audio, pengaturan sebelum melakukan penyiaran, sampai pengaturan transisi, pengambilan sudut kamera, dst.

Interaksi karakter 3D (Avatar) agar bisa merepresentasikan user yang bergabung dan mampu berkomunikasi, berbicara melalui mic, berjalan, menggerakkan tangan, dan berinteraksi dengan perangkat virtual sekitar, maka pengembangan avatar user dengan gerakan realistis dan lebih nyata mutlak 
dibutuhkan. Serta dibutuhkan sinkronisasi di setiap pengguna, sehingga setiap karakter dan objek yang ada pada laboratorium maya tersebut terlihat sama di setiap user. Gambar 2.3 merupakan contoh saat dua pengguna yang berada pada satu pandangan yang sama.
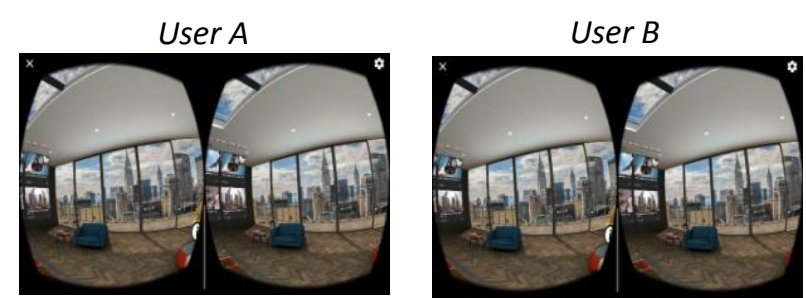

Gambar 2.3. Pengguna A dan pengguna B ketika menggunakan alat VR dan berada pada satu sesi pembelajaran/praktikum yang sama

Untuk mensinkronkannya, digunakan plugin network manager dengan konsep clientserver yang sudah tersedia di game engine Unity sebagaimana digambarkan pada Gambar 2.4. Plugin ini biasanya memang sering digunakan pengembang untuk berbagai kebutuhan multiplayer pada simulasi maupun game.

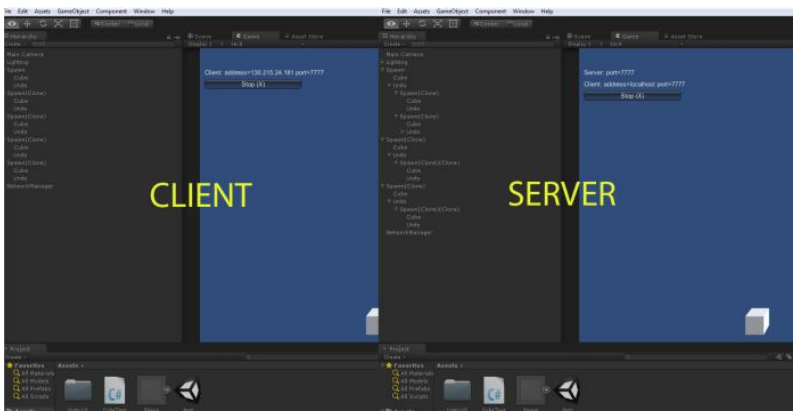

Gambar 2.4. Contoh Instalasi Network Manager ClientServer menggunakan plugin yang ada di Unity Game Engine

\subsection{Instalasi Package VR pada Unity Game Engine}

Package dan plugin dalam pengembangan simulator ini berfungsi sebagai satuan perangkat lunak yang menjembatani antara headset VR yang digunakan (HTC Vive atau Oculus) dan game engine Unity agar bisa terintegrasi dengan baik. Disini digunakan SDK Steam VR. Dengan SDK ini, ketika perangkat Virtual Reality yang digunakan (seperti HTC Vive atau Oculus) sudah mendukung SteamVR, maka pengembang tidak perlu melakukan konfigurasi perangkat secara hard-code lagi dari simulasi media praktikum yang dikembangkan. Gambar 2.5 merupakan plugin yang yang digunakan dalam pengembangan ini.

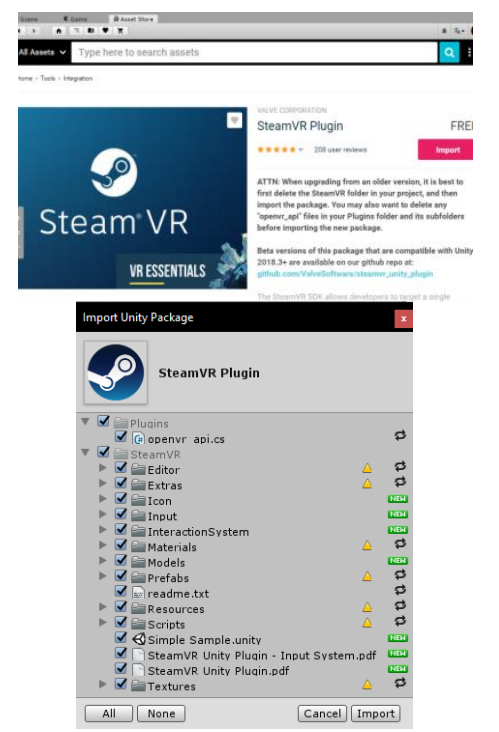

Gambar 2.5. SteamVR untuk Unity

\subsection{Sekenario Ujicoba Simulator}

Dalam pengujian prototype simulator ini, sekenario praktikum akan diujikan pada penggunaan switcher televisi dan pengaturan kamera secara sederhana yang merupakan aktivitas dasar dalam praktikum di Lab Broadcasting PENS. Dengan dua pengguna sebagai pemegang alat kamera dan switcher, masing-masing akan diuji komunikasinya, avatar keduanya, dan bagaimana mereka menyentuh masing-masing perangkat virtual tersebut. 


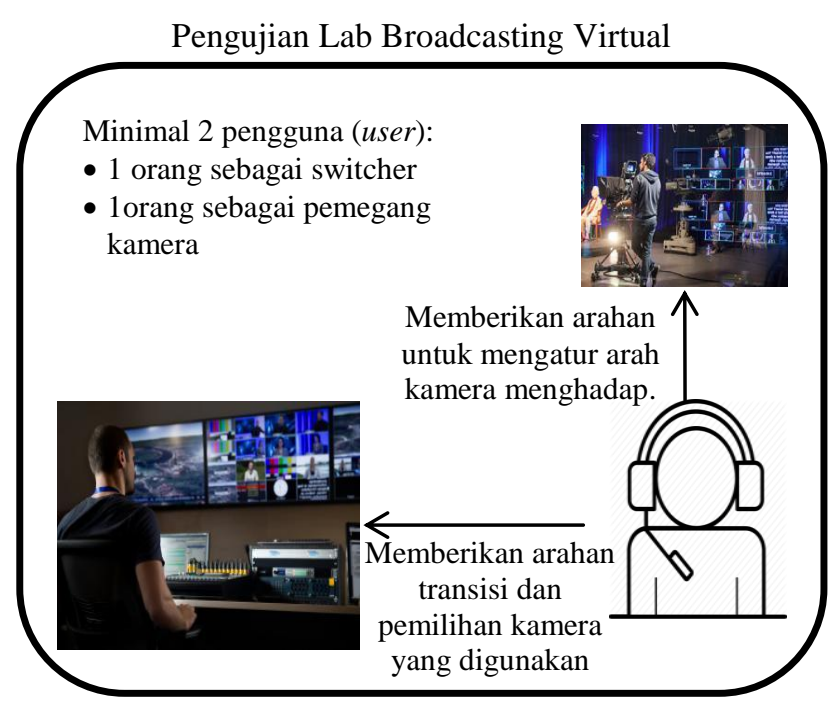

Gambar 2.6. Pengujian Simulasi Praktikum di Lab Broadcasting Virtual menggunakan Switcher Televisi VPS-700OU dan kamera

Secara umum sebagaimana digambarkan pada Gambar 2.6, prototype diujikan dengan user yang berperan sebagai menejer dan pemegang switcher terkait kemana kamera harus diarahkan, transisi apa yang akan digunakan, dan harus seperti apa model pengambilan gambarnya

\section{Hasil Pengujian}

\subsection{Kebutuhan Perangkat dalam Pengujian}

Dalam melakukan pengujian sistem, dibutuhkan perangkat komputer yang mendukung kebutuhan server dan client, serta spesifikasi yang memadai untuk menggunakan perangkat Virtual Reality. Spesifikasi komputer dan perangkat yang digunakan yang digunakan dalam pengujian sebagaimana Tabel 3.1

Tabel 3.1 Spesifikasi perangkat

\begin{tabular}{|c|l|}
\hline Peralatan & \multicolumn{1}{|c|}{ Spesifikasi } \\
\hline Server dan Client & - Processor Intel i7-7700 (4 \\
& CPUs) $\sim 3.60-4.20 \mathrm{GHz}$ \\
& - Graphics Card nVidia GTX \\
& $10606 \mathrm{~GB}$ \\
& - RAM 16 GB \\
& - Operating System Windows \\
& 10 Education 64-bit. \\
& - Program SteamVR \\
\hline Perangkat Virtual & - HTC Vive atau Oculus Rift @ \\
Reality & 1 PC (Server/Client) \\
\hline
\end{tabular}

\subsection{Pengujian Multiplayer Virtual Reality}

Pengujian fitur multiplayer sekaligus kompatibilitas dalam penggunaan perangkat Virtual Reality pada server maupun client dilakukan secara berdampingan agar dapat dilihat aksinya dari klien atau server. Keduanya dihubungkan melalui jaringan internet dengan masing-masing Head Mounted Display HTC Viive dan Oculus Rift. Gambar 3.1 merupakan Langkah ujicoba multiplayer simulator

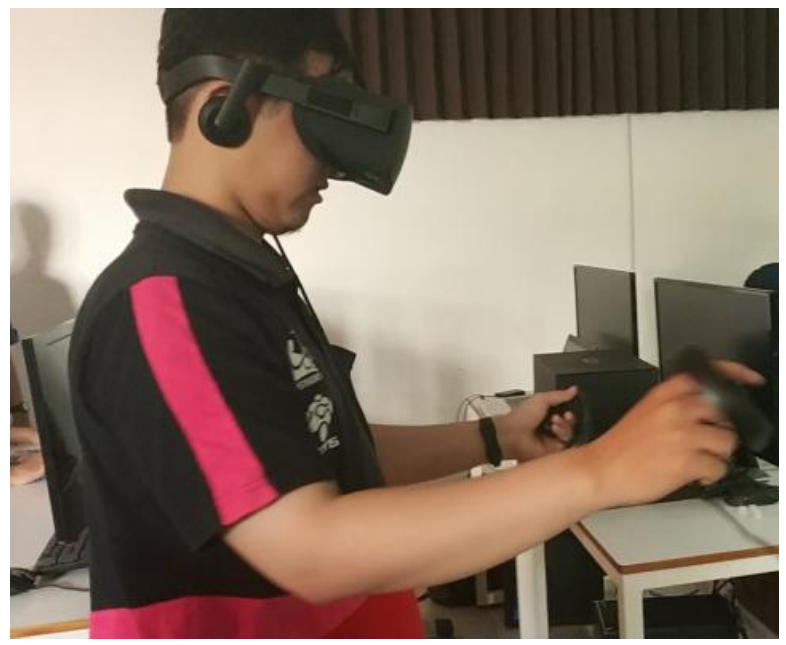

Gambar 3.1 Percobaan menggunakan perangkat Virtual Reality secara multiplayer di sisi Server

Pada gambar 3.1 merupakan ujicoba perangkat Virtual Reality di sisi Server, dan dilihat apakah obyek dan avatar akan berjalan dan bergerak juga di sisi Client atau tidak. Dari percobaan tersebut didapatkan pergerakan yang realtime pada sisi klien sebagimana Gambar 3.2.

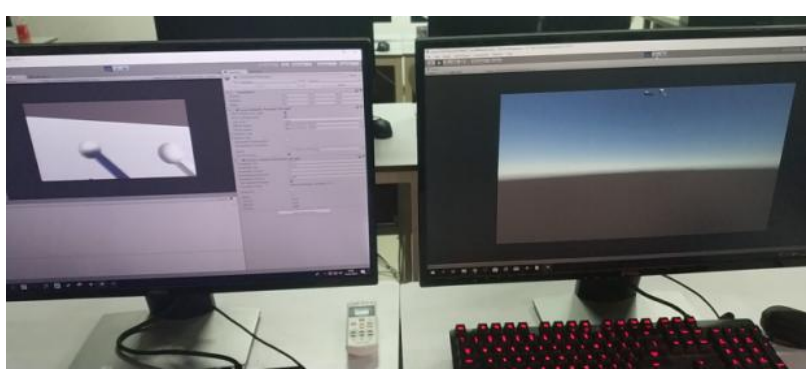




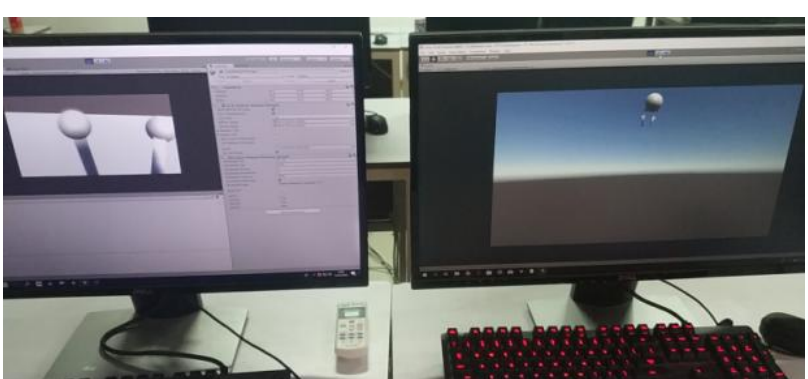

Gambar 3.2. Gambar pergerakan controller Virtual Reality antara Server dengan Client

\subsection{Pengujian Avatar User}

Avatar diujikan dengan beberapa proses interaksi, seperti memencet tombol switcher, melihat ke kru lain, sampai bersalaman secara virtual. Karakter juga dibangun dengan gerakan Inverse Kinematics sehingga dapat bergerak dengan realistis.

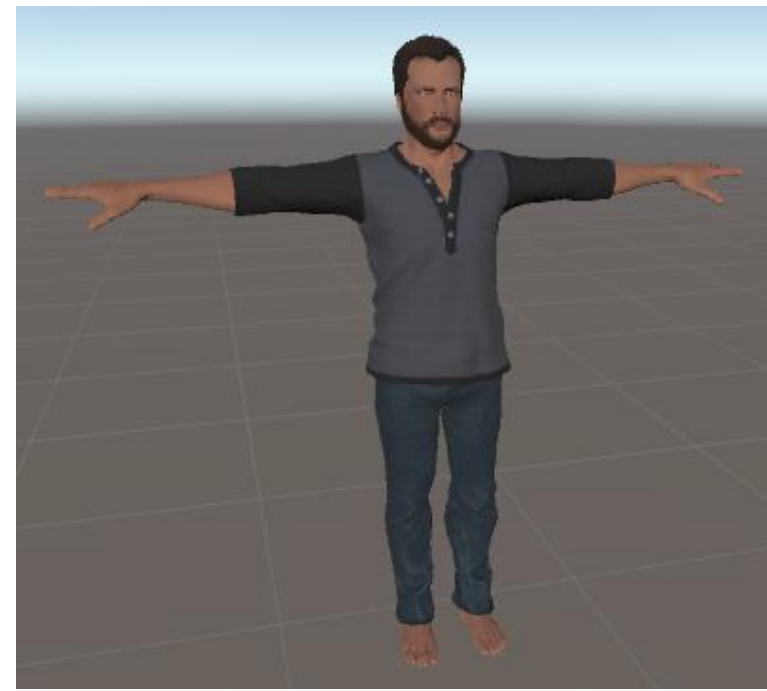

Gambar 3.3. Karakter 3D yang akan digunakan dalam pengujian ini

Dengan desain rigging yang baik dan skema animasi yang ada pada Unity, maka karakter avatar dapat terlihat bergerak dengan natural, sesuai arah tangan kita. Gambar 3.4 merupakan beberapa hasil avatar yang berjalan saat melakukan praktikum pada lab. broadcasting virtual.
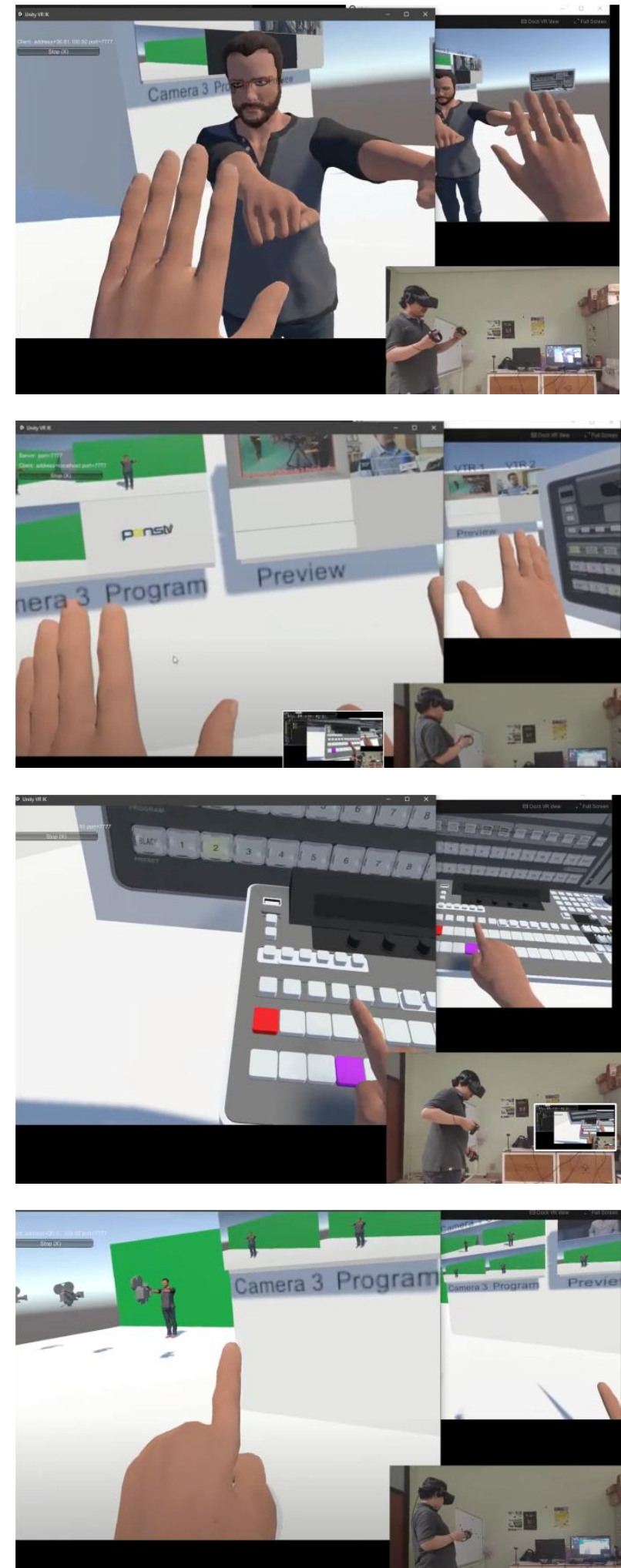

Gambar 3.4. Beberapa adegan penggunaan lab broadcasting virtual dengan simulator VR ini. 


\section{Saran}

Dari hasil simulasi untuk laboratorium broadcasting virtual ini, ada beberapa hal yang bisa digaris bawahi:

1. Tentunya konsep ini bisa dikembangkan pada laboratorium virtual lain dengan memanfaatkan teknologi yang sama seperti yang telah dibahas pada makalah ini. Cukup kita mengganti asset dan sekenarionya sesuai kebutuhan lab virtual apa yang ingin dibangun.

2. Simulator lab broadcasting ini juga masih dalam produk prototype, sehingga jika dikembangkan lebih jauh seperti menambah perangkat broadcasting yang lebih komplit atau dengan menambah lebih banyak kru yang tergabung sehingga benar-benar bisa menggantikan lab broadcasting yang ada, akan banyak pihak yang membutuhkan, baik dari institusi pendidikan atau pelatihan penyiaran professional.

\section{Daftar Pustaka}

[1] Official Website of Labster. http://www.labster.com. Diakses Juni 2017

[2] Sritusta Sukaridhoto, dkk. A Design of 3D Virtual Reality Chemistry Lab with Hand Gesture Interaction for Education. The 5th Annual Basic Science International Conference, UB Malang. April 2015.

[3] Moh. Zikky, Miftakhul Firdaus, Kholid Fathoni, Interactive Distance Media Learning Collaborative Based on Virtual Reality with Solar System Subject, 27 Juni 2018.

[4] Offivial web For-A Company Limited https://www.for-a.com/products/vps700/ diakses Maret 2020.

[5] Official Web Sony Electronics Asia Pacific Pte. Ltd. https://pro.sony/en MY/products/4kand-hd-camera-systems/hdc-2000w. Diakses Maret 2020. 